\title{
Performance Assessment of Installed Solar PV System: A Case Study of Oke-Agunla in Nigeria
}

\author{
Olawale Saheed Ismail, Olusegun Olufemi Ajide*, Fredrick Akingbesote \\ Department of Mechanical Engineering, University of Ibadan, Ibadan, Nigeria \\ Email: "ooe.ajide@mail.ui.edu.ng
}

Received May 2, 2012; revised June 1, 2012; accepted June 15, 2012

\begin{abstract}
Solar Photovoltaic (PV) can be considered as one of the most reliable and promising renewable systems. This is of great importance for developing countries like Nigeria especially in the rural communities where there is little or no access to electricity. The use of solar energy will no doubt contribute to the improvement of the living conditions of these villagers. Solar PV systems have been installed in some villages in Nigeria but unfortunately, the expected benefits from using these systems have been jeopardized. The objective of this work is to embark on performance assessments of installed Solar PV system in Oke-Agunla, Akure local government of Ondo State in Nigeria. Visits were conducted to the village; equipments on ground were examined while the people were interviewed. Both functional and non-functional facilities were traced to their manufacturers using the identification data on them and rated to ensure their efficiencies. Energy demands were also prorated, and observed the need to improve on the present energy supplied. Results of the assessments shows that PV facilities used were inadequate, trained technicians were not available giving room for quacks working on the facilities occasionally resulted in further complications and poor facilities maintenance. The assessment result shows that just $14.52 \%$ of the $4.5 \mathrm{~kW}$ installed solar PV was utilized due to significant malfunctioning and deterioration in performance. It can be concluded from this study that the installed solar PV systems was inefficient as a result of poor maintenance, lack of technical know-how and inability of the project contractors or managers to take these factors into consideration while embarking on the solar PV installations.
\end{abstract}

Keywords: Solar PV; Installations; Oke-Agunla; Energy Supply; Assessment and Deterioration

\section{Introduction}

An adequate and reliable power supply system is essential for any developing country like Nigeria. Globally, the adoption of Solar PV in rural communities is attracting more researchers' interests in the recent times. Akanksha and Tara [1] carried out assessment and evaluation of PV based decentralized rural electrification. According to the authors, Photovoltaic (PV) technology is one of the first among several renewable energy technologies that was adopted globally in meeting basic electricity needs of rural areas that are not connected to the grid. Solar photovoltaic (PV) systems are reckoned to be viable alternatives for reliable power supply, particularly for small loads in remote areas and rural communities [2]. The status and potential of photovoltaics in Nigeria were extensively discussed in the paper. One of the most promising renewable energy technologies is photovoltaics [3]. Photovoltaics (PV) are truly elegant means of producing electricity on site, directly from the sun, without concern for energy supply or environmental harm.

\footnotetext{
"Corresponding author.
}

These solid-state devices simply make electricity out of sunlight, silently with no maintenance, no pollution, and no depletion of materials. Bhubaneswari et al. [4] reviewed the photovoltaic technology, its power generating capability, the different existing light absorbing materials used, its environmental aspect coupled with a variety of its applications. The different existing performance and reliability evaluation models, sizing and control, grid connection and distribution were also highlighted in the work. Ahmed et al. [5] asserted that Solar photovoltaic is of great importance for developing countries like Mauritania and Senegal, without which many villages in these countries would still be facing lack of electricity services for many years to come. The use of solar energy can contribute to the improvement of the living conditions of these populations. Obeng et al. [6] illustrates the intersectoral linkages of solar PV electrification and indicators on education, health, information acquisition, agriculture and micro-enterprises in Ghana. They also reviewed sustainability related issues including costs and market barriers, subsidies, stakeholders' involvement, political and policy implications, which are critical fac- 
tors for sustainable market development of solar PV and other renewable. Finally, a common framework was developed to provide a basic understanding of how solar PV electrification impacts on energy-poverty. The conceptual framework developed in the paper provided a structure of the interrelated concepts and principles relevant to the issues under review. To expand the frontiers of knowledge, the author recommended that future studies should add to the number of indicators that can be gathered from the review with the goal of reducing energy-poverty and enhancing quality of life associated with access to solar PV in rural and peri-urban areas without access to grid-electricity. Jack [7] adapted an assessment tool based on lifecycle-sustainability framework and applied it to assess Solar Home System (SHS) projects in rural Vanuatu. Three SHS project sites with different project basis were chosen for the case studies of the work. For these case studies, the assessments was done both during and after the completion of the work and were compared using the lifecycle assessment methodology to help determine best practices for rural SHS projects in Vanuatu. Recommendations of this work include modifications and weighted emphasis on the assessment tool for more relevance under SHS project context. The work included rural area specific SHS component selection, design, and economic considerations. He observed technical design error margin in the conceptual design life stage and system hardware robustness from environmental conditions and user abuse are found to be factors that can lead to system longevity. Agbo and Oparaku [8] carried out an assessment study of the positive and future prospects of solar water heating in Nigeria. The hot water demand in public and private sector organizations can also be met with Solar Hot Water (SHW) systems. Their paper assesses the principles and technology of solar water heating, the current state of development, and the dissemination of the systems and their future prospects in Nigeria. The assessment result shows that the level of adoption of SHW heating technology in the Nigerian economy is very low at the moment, despite the fact that many prototypes of the systems have been well researched and developed within the country. The authors asserted that enormous potentials exist in the household, health, agricultural, education, and industrial sectors. Widespread dissemination of the systems to meet up the demands in these sectors will depend on the removal of several limitations. Bold initiatives by the public and private sector, the financial institutions, and international agencies are required in order to remove these limitations. The benefits to the citizens, the economy, and the environment thereafter cannot be overemphasized. The effect of ambient temperature on the performance of an Amorphous Silicon Photovoltaic
System (ASPS) was studied by Sanusi et al. [9] in Ogbomosho area of Nigeria. The authors monitored the variation in power output of the system with ambient temperature of the area for three years, 2006, 2007, and 2008. From the results, it was observed that a direct proportionality between the power output performance of the system and the ambient temperature exist. This was confirmed from the values of the correlation coefficient, $\mathrm{R}$, when the power output of the system was correlated with the ambient temperature. The results also indicated that the ambient temperature must be taken into account when designing and predicting the performance of the ASPS in the tropical parts of Nigeria. Various programmes have been established over recent year so as to provide rural communities in South Africa with electric power by means of photovoltaics. PV systems have been installed successfully at numerous schools and clinics, yet experiences following installation have been mixed. According to Klunne [10], many systems have fallen into a poor state of repair, and are vulnerable to criminal activity. Rizwan et al. [11] carried out an assessment of SPV (solar photovoltaic) system using ANN and VHDL. Experimental database of meteorological parameters like temperature and daily global solar irradiance for various Indian stations were used to assess the SPV system performance. The inputs of the ANN are the daily total irradiance and mean average temperature while the outputs are the current and voltage generated from the system. Subsequently, the neural network corresponding to SPV system is implemented using VHDL language based on the saved weights and bias of the network. The given model based on ANN and VHDL permit to evaluate the performance of SPV system using only the meteorological parameters and involves less computational efforts, and it can be used for predicting the output electrical energy from the system. Barhdadi and Zakey [12] applied the PVGIS method for performance assessment of the first grid-connected PV Micro-power plant in Africa. PVGIS approach provides analysis and assessment of in-site solar energy resources and predicts with good accuracy the potential of PV systems in term of electricity production. Findings showed that annual total power generation of the micro-power is slightly higher than that initially expected at the installation stage and actually measured. The yearly predicted and measured power production values agreed to about $2 \%$. However, individual monthly production can have larger discrepancy. The work was able to develop the integration of new components notably predictions from the radiation scheme in the ICTP-Regional Climate Model (RegCM).

\section{Methodology}

A pre-survey was carried out to identify and map out 
area of research focus after which a set of questionnaire administered in clusters and in-depth interview of the residents were carried out. This can be seen in Figure 1 while conducting interview with a village elder and the regent, princess Olakitan Owoeye. The information gathered from these sources was subjected to content analysis using the appropriate statistical model. It can be seen in Figures $\mathbf{2}$ and $\mathbf{3}$ that visits were conducted to the village; equipments on ground were examined while the people were interviewed by means of questionnaire and oral (see Figure 1). Figure 2 shows the installed solar street lights while Figure $\mathbf{3}$ illustrates typical installed home solar lights in Oke Agunla. Both functional and non-functional facilities were traced to their manufacturers using the identification data. The assessment focuses

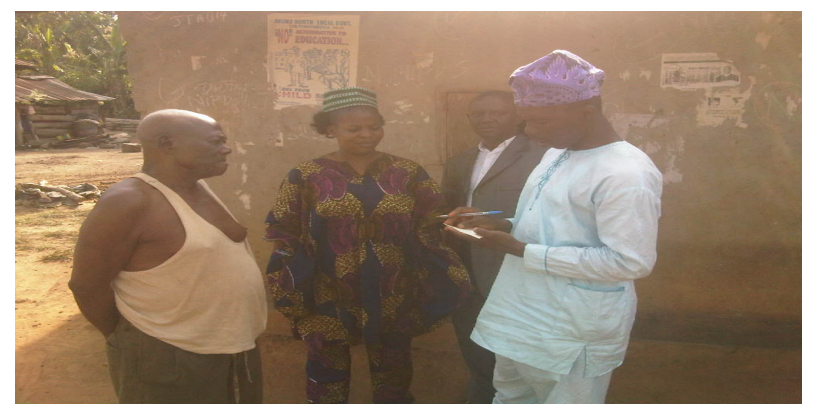

Figure 1. Conducting Interview with a village Elder and the Regent, Princess Olakitan Owoeye.

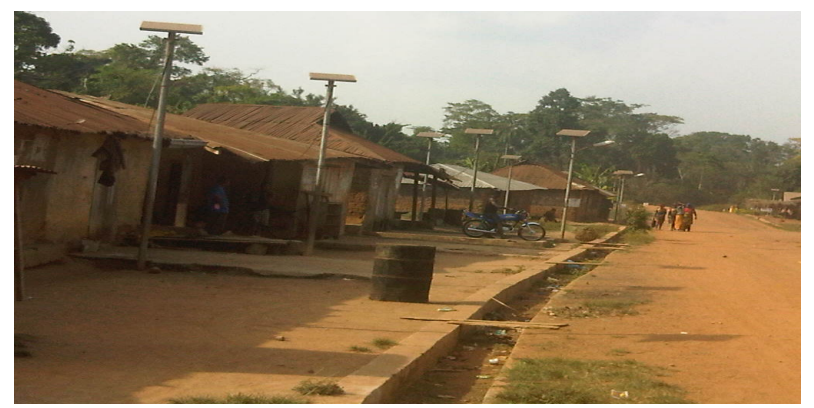

Figure 2. Installed solar street lights in Oke-Agunla, Ondo State, Nigeria.

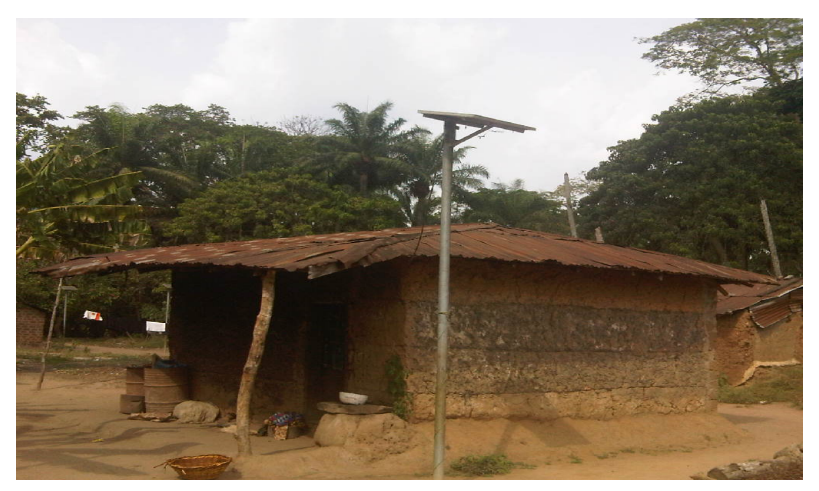

Figure 3. Installed home solar lights. on Solar Street Light (SSL), Solar Home System (SHS) and Solar Clinic Installation (SCI) based on the gathered information. The appliances in the village were critically assessed and expected loads to be connected to PV system were calculated.

\section{Results and Discussion}

\subsection{Profiles of Solar PV Installation in Oke-Agunla, Ondo State}

Table 1 shows data obtained both through interview, site visitations and facilities inspections.

\subsection{Infrastructure}

\subsubsection{Solar Street Lights (SSL)}

The solar street lights numbering 10 are all off-grid solutions. They are AC powered with top-of-pole mounted solar modules. In the first few months of installation, the beneficiaries enjoyed night lighting from dusk to dawn every night and the photocell intelligence worked as installed. However, the system performance began to deteriorate at about 28 months. The deficiencies noticed in the SSL infrastructure are twofolds. Due to the short length of the light poles, the distance between light poles were short, and this means there are more poles being used. From design perspective, the higher the poles, the fewer the number to be used because of the wider area of illumination coverage. Paint coating on the poles are peeling off. The silver paint coating on the lighting poles has been peeled off, leaving a rusty surface. Use of none galvanized metal poles. The metal poles used for the lighting system were not galvanized. Galvanized metal poles have higher corrosion resistance than non-galvanized materials. Poor Aesthetics was noticed where good design and finish were not given a priority on the SSL job. The battery box height was rather low, making it easily accessible to unauthorized people. Earth wires in some installed were hanging which has exposed a substantial number of the earthen wires to abuse by passer. The SSL lamps were AC powered hence, each unit has an inverter embedded to invert the DC. This led to some power losses.

\subsubsection{Solar Home System (SHS)}

All the fourty stand alone systems are off-grid solutions. Each unit consists of two components; outdoor unit and indoor unit. The outdoor unit is a top-of-pole mounted single $70 \mathrm{~W}$ solar module, working at 5.5 peak sun hours per day, the module has the capacity to generate 385 Watt-Hrs per day baring system losses. Performances were quite good at installation. However, due to system inadequacies bothering on maintenance, the effectiveness was short lived. A large number of the systems stopped 
Table 1. Profiles of solar PV installation in Oke-Agunla Village, Ondo State.

\begin{tabular}{|c|c|c|}
\hline SN & ITEM & REMARK \\
\hline 1 & Estimated Population of the Village & 1050 \\
\hline 2 & Average Number of Households in the Village & 150 \\
\hline 3 & Average Number of Persons per Household & 7 \\
\hline 4 & Number of Households Connected & $\begin{array}{l}\text { 1) } 40 \text { off-grid, stand alone } 70 \mathrm{~W} \text { panels per household with battery. } \\
\text { 2) } 10 \text { off-grid, stand alone } 70 \mathrm{~W} \text { panels for street light poles. } \\
\text { 3) } 10 \text { off-grid, stand alone } 70 \mathrm{~W} \text { panels for vaccine refrigeration. } \\
\text { 4) } 3 \text { off-grid, stand alone } 70 \mathrm{~W} \text { panels for a church, a mosque, a school, a palace. }\end{array}$ \\
\hline 5 & Type of Solar PV Installation & Solar Home System (SHS), Solar street Lights (SSL) and Solar Clinic System (SCS) \\
\hline 6 & Year of Installation of PV System & June 2006, commissioned by former President Olusegun Obasanjo. \\
\hline 7 & Capacity of the PV (Panels) Installed & $4.5 \mathrm{~kW}$ \\
\hline 8 & Major Components of the PV Installation & $\begin{array}{l}70 \text { solar panels and accessories, } 50 \text { storage batteries, } 2 \text { inverters, } 2 \text { battery controllers } \\
\text { and } 8 \text { ELCB breakers, } 2 \text { big deep freezer, } 15 \mathrm{~W} \text { bulbs, } 200 \mathrm{~W} \text { bulbs. }\end{array}$ \\
\hline 9 & Objective of the PV Installation & Generate Electricity for the village. \\
\hline 10 & Sponsors of the PV Installation & JICA, ECN and Ondo State Government. \\
\hline 11 & Status of the Installation & Working well but not enough to meet village demand. \\
\hline 12 & Monitoring \& Evaluation & ECN, PHCN \\
\hline 13 & Sustainability & $\begin{array}{l}\text { Continuous training of village technicians who work with experts at ECN for mainte- } \\
\text { nance of the installation. }\end{array}$ \\
\hline
\end{tabular}

working thirty months after installation. Deficiencies in terms of delivered energy inadequacy are enormous. While the SHS passed the proof of concept as a viable source of electricity for rural dwellers, this particular deployment (Oke-Agunla solution) failed to go beyond meeting the need for just 2 lighting points (Lighting) in the homes. A typical home (urban or rural) conforms to the lighting, ventilation, entertainment, refrigeration, Air Conditioning, Heating and Cooking. LIVERAHC, a residential energy requirement model, whereby lighting $L$ is the most basic electricity need. Almost all electrical household appliances in Nigeria are AC powered. However, the deployed SHS pumps out only DC power to run the lights and provide a single power outlet for DC appliances. Therefore, except a householder invests a converter; almost no other appliance in the house may run off the provided electricity. Lack of spares for component replacement and mishandling of cables by unauthorized persons also constituted the deficiencies.

\subsubsection{Solar Clinic System (SCS)}

All are applicable as stated above, but needs complete system upgrade because of various applications that are more energy consuming such as refrigerating (using 600 Watts of installed photovoltaic modules). It was commissioned by the then President Olusegun Obasanjo on June 25, 2006. The Solar Clinic System also consists of two parts Outdoor Unit (ODU) and Indoor Unit (IDU). The
SCS performed more favorably for about seven months after installations. While it could not be said to operate at peak performance, the SCS still provides electricity for running the village clinic. The solar modules were enclosed within a wire mesh providing security for the facility. The SCS provide two energy services at the clinic: Lighting and Refrigeration. Unfortunately, only two units out of the ten installed lighting points were functional in the clinic. The rest were burnt out as losses. The DC fridge was only used to refrigerate vaccines in the clinic. Lack of AC power points in the clinic and problem of spares for component replacement greatly affected the installed PV system in the clinic.

\subsection{Human Capacity}

During the visit to the village, the performance of the technician in charge of the facilities was below average; this is because the man could not answer some technical questions, apparently due to dearth of knowledge. Secondly, it was obvious that he did not have the time for the system maintenance assignment, because of his other personal commitment as a peasant farmer coupled with his spiritual responsibility as a Pastor. The demands of this office incapacitated him from giving desired attention to the equipment maintenance. On site visit revealed inadequate personnel training. The project maintenance officer is deficient in training because he has never attended any formal training or retraining on solar instal- 
lation maintenance. Lack of motivation also affected performance of the project maintenance officer .He was not adequately catered for in terms of remuneration by the beneficiaries, the donor agency or the government. This culminated in an ugly scenario where the community funds meant for minor maintenance was once misappropriated by the subject. The project maintenance officer did not have any planned structure of carrying out maintenance. This was evident at the state of disrepair of the facilities at the time of visit to the village. The report from the beneficiaries and the maintenance officer was that the solar PV performed excellently when first installed. However, the system performance integrity became compromised over time due to minor issues such as end-use appliance failure and non replacement. There was no adequate awareness and sensitization program mounted to educate the end-users. This lack culminated in improper handling of equipment, battery over discharge, inadequate charging of battery, battery overcharging, use of inappropriate lighting bulbs and appliances.

\subsection{Estimated Electric Power Load of Household Appliances}

The electric load calculated results for all the household appliances used by both lower class $(15 \%$ of the total Population) and Upper class (85\% of total population) of Oke-Ajagunla village is shown and discussed as follow:

Lightening - $15 \%$ of allotted energy to be made up of

1) Ten points of LED bulbs of 10 watts each $=100$ watts;

2) Information -2 laptops of 30 watts each $=60$ watts;

3) Ventilation -2 fans of maximum voltage $=170$ watts;

4) Entertainment - one television $=85$ watts;

5) Refrigeration - one Refrigerator $=270$ watts;

Total minimum required energy for upper class $=685$ watts AC.

Multiply by 1.2 to account for inverter $20 \%$ loss $=822$ watts DC.

Minimum energy requirement (LVE) for $85 \%$ of citizens

1) Lightening - five points of LED bulbs of 10 watts each $=50$ watts;

2) Ventilation -2 fans of maximum voltage $=170$ watts;

3) Entertainment - one television $=85$ watts;

Total minimum required energy for the low class $=$ 305watts AC.

Multiply by 1.2 to account for inverter 20\% loss $=366$ watts DC.

The results presented above shows that 1188 watts $(1.188 \mathrm{~kW})$ was the approximate power demand of the village but only $55 \%$ (653.4 watts) of this was utilized. This is far below the installed 4500 watts $(4.5 \mathrm{~kW})$ capacity. The result implies that just $14.52 \%$ of the installed solar PV was utilized due to significant malfunctioning and deterioration in performance.

\section{Conclusion}

Study has shown that the installed $4.5 \mathrm{~kW}$ solar PV systems at Oke-Agunla village was underutilized as a result of the systems malfunctioning or performance deterioration arising from poor maintenance, lack of technical know-how and inadequate training as well as ill-experience of the project managers. This assessment no doubt enriches the understanding of several factors that need to be integrated into the processes of solar PV sizing and installations especially in rural communities. There is a strong believe that the efficiency and performance of installed solar PV systems will be greatly improved. Surely, solar PV systems will become a beacon for reliable power supply in villages with no access to national grid.

\section{REFERENCES}

[1] C. Akanksha and C. Tara, “Assessment and Evaluation of PV Based Decentralized Rural Electrification: An Overview," Renewable and Sustainable Energy Reviews, Vol. 14, No. 8, 2010, pp. 2266-2278. doi:10.1016/j.rser.2010.04.005

[2] O. U. Oparaku, "Photovoltaic Systems for Distributed Power Supply in Nigeria,” Renewable Energy, Vol. 25, No. 1, 2002. pp. 31-40. doi:10.1016/S0960-1481(00)00203-2

[3] S. Steven, "Building Integrated Photovoltaics (BIPV)," Whole Building Design Guide (WBDG), Washington DC 2011.

[4] P. Bhubaneswari, S. Iniyan and G. Ranko, "A Review of solar Photovoltaic Technologies," Renewable and Sustainable Energy Reviews, Vol. 15, No. 3, 2011, pp. 16251636. doi:10.1016/j.rser.2010.11.032

[5] M. Y. Ahmed, I. Youm and A. Kader, "Behaviour and Performance of a Photovoltaic Generator in Real Time,” International Journal of the Physical Sciences, Vol. 6, No. 18, 2011, pp. 4361-4367.

[6] G. Y. Obeng and H. Evers, "Solar PV Rural Electrification and Energy-Poverty: A Review and Conceptual Framework with Reference to Ghana,” Munich Personal RePEc Arhive (MPRA), Munich, 2009, Paper No. 17136. http://mpra.ub.uni-muenchen.de/17136/MPRA

[7] T. C. Jack, “Assessment of Solar Home Systems (SHS) for Isolated Rural Communities in Vanuatu Using Project Lifecycle/Sustainability Framework,” M.Sc Report, Department of Environmental Engineering, Michigan Technological University, Houghton, 2010.

[8] S. N. Agbo and O. U. Oparaku, "Positive and Future Prospects of Solar Water Heating in Nigeria," The Pacific Journal of Science and Technology, Vol. 7, No. 2, 2006, pp. 191-198.

[9] Y. K. Sanusi, G. R. Fajinmi and E. B. Babatunde, "Ef- 
fects of Ambient Temperature on the Performance of a Photovoltaic Solar System in a Tropical Area," The Pacific Journal of Science and Technology, Vol. 12, No. 2, 2011, pp. 176-180.

[10] W. Klunne and C. Mugisha, "Learning a Lesson-Assessing PV Programmes in Rural South Africa,” Renewable Energy World, Vol. 5, 2002, pp. 83-97.

[11] M. Rizwan, M. Jamil and D. P. Kothari, “Assessment of
SPV System Using ANN and VHDL,” 2010 Joint International Conference on Power Electronics, Drives and Energy Systems (PEDES) \& 2010 Power India, Delhi, 20-23 December 2010, pp. 1-7.

[12] A. Barhdadi and A. S. Zakey, "Performances Assessment of the First Grid-Connected Photovoltaic Micro-Power in Africa: The PVGIS Approach,” Moroccan Journal of Condensed Matter, Vol. 12, No. 1, 2010. 